\title{
CARACTERÍSTICAS BOTÂNICAS, EFEITOS TERAPÊUTICOS E PRINCÍPIOS ATIVOS PRESENTES NO PEQUI (Caryocar brasiliense)
}

\author{
Luciana Silva de Carvalho' \\ Kleber Fernando Pereira ${ }^{2}$ \\ Eugênio Gonçalves de Araújo ${ }^{1 *}$
}

DE CARVALHO, L. S.; PEREIRA, K. F.; DE ARAÚJO, E. G. Características botânicas, efeitos terapêuticos e princípios ativos presentes no pequi (Caryocar brasiliense). Arq. Cienc. Saúde UNIPAR, Umuarama, v. 19, n. 2, p, 147-157, maio/ago. 2015.

\begin{abstract}
RESUMO: O cerrado é um bioma com uma grande quantidade de exemplares botânicos utilizados por populares para o tratamento de diversas enfermidades. A avaliação do potencial terapêutico de plantas medicinais e de alguns de seus constituintes, tais como flavonoides, alcaloides, triterpenos, sesquiterpenos, taninos, lignanas e outros, tem sido objeto de incessantes estudos, a partir dos quais já foram comprovadas ações farmacológicas por meio de testes pré-clínicos com animais. Esta revisão da literatura tem o propósito de apresentar os principais princípios ativos já identificados no Caryocar brasiliense e também o que se tem descoberto e comprovado, cientificamente, quanto à atividade terapêutica deste fruto, demonstrando a sua importância para o desenvolvimento de possíveis terapias contra variadas doenças. PALAVRAS-CHAVE: Pequi; Terapêutica; Cerrado.
\end{abstract}

\section{BOTANICAL FEATURES, THERAPEUTIC EFFECTS AND ACTIVE INGREDIENTS PRESENT IN PEQUI (Caryocar brasilia)}

\begin{abstract}
The Cerrado is a biome with several botanical samples used by the population to treat various diseases. The evaluation of the therapeutic potential of medicinal plants and some of their constituents, such as flavonoids, alkaloids, triterpenes, sesquiterpenes, tannins, lignans and others, has been the subject of incessant studies, from which pharmacological actions have been proven by means of preclinical animal tests. This literature review aims to present the main active ingredients that have been identified in Caryocar brasiliense and also what has been discovered and scientifically proven about the therapeutic activity of this fruit, showing its importance for the development of potential therapies for various diseases.
\end{abstract}

KEYWORDS: Pequi; Therapeutic; Cerrado.

\section{Introdução}

A utilização das plantas com finalidade terapêutica data dos primórdios da civilização e foi transmitida entre as gerações por milhares de anos. O uso das plantas para fins medicinais tem despertado um grande interesse pelo conhecimento da composição química das plantas e contribuído para o estudo das espécies de origem vegetal, buscando analisar seu princípio ativo, mecanismo de ação e presença ou ausência de eficácia no controle ou tratamento de determinadas enfermidades (MACIEL; PINTO; VEIGA, 2002; SIMÕES, 2004).

Embora o Brasil possua a maior diversidade vegetal do mundo com cerca de 60.000 espécies vegetais superiores catalogadas, muitas delas de uso na medicina popular não foram estudadas quanto à composição química, ações farmacológicas e reais indicações terapêuticas comprovadas. Apesar de inúmeros estudos relatarem sobre a eficácia de extratos de plantas em tratamentos terapêuticos em função dessas propriedades químicas, sabe-se que apenas $8 \%$ foram estudadas para pesquisas de compostos bioativos e 1.100 espécies foram avaliadas com relação às propriedades medicinais. As plantas avaliadas representam no contexto mundial um importante potencial econômico, podendo contribuir efetivamente na busca de novos produtos bioativos (GUERRA; NODARI, 2001; RATES, 2001; PEREZ, 2004; GURIB-FAKIM, 2006; MOLL, 2006).

Segundo a OMS, 65 a $80 \%$ da população mundial, especialmente em países em desenvolvimento, ainda confiam nos produtos à base de plantas medicinais no tratamento de suas doenças. Essas pessoas valorizam e utilizam remédios naturais por serem considerados menos tóxicos e, consequentemente, menos agressivos. No entanto, a "aplicação terapêutica das plantas não dispensa as evidências científicas, os requisitos de segurança, eficácia, qualidade e uso racional e sustentável" (BARBOSA, et al., 2001; RAHMAN; SINGHAL, 2002; ARAÚJO, 2008).

O bioma cerrado apresenta uma grande variedade de plantas utilizadas por populares para o tratamento de doenças. Tal hábito parte do pressuposto de que as plantas utilizadas, além de possuírem atividade terapêutica, são desprovidas de efeitos tóxicos. A avaliação do potencial terapêutico de plantas medicinais e de alguns de seus constituintes, tais como flavonoides, alcaloides, triterpenos, sesquiterpenos, taninos, lignanas e outros, tem sido objeto de incessantes estudos, a partir dos quais já foram comprovadas ações farmacológicas através de testes pré-clínicos com animais (CARLINI, et al., 1988; CECHINEL; YUNES, 1998).

Dentre as frutíferas nativas do cerrado, destaca-se o pequizeiro (Caryocar brasiliense), considerado uma das espécies de maior interesse econômico, principalmente devido ao uso do seu fruto na culinária, a extração de óleos para a fabricação de cosméticos e suas propriedades terapêuticas. A farinha do epicarpo e mesocarpo externo do pequi (casca) é muito rica em fibra alimentar total, além de possuir carboidratos, cinzas, magnésio, cálcio, manganês e cobre. Além disso, esse vegetal apresenta uma elevada quantidade de fenóis, utilizando-se na medicina tradicional as folhas de C. brasiliense Cambess., na forma de decocto, contra gripes, resfriados, doenças inflamatórias, cicatrização de feri-

DOI: https://doi.org/10.25110/arqsaude.v19i2.2015.5435

${ }^{1}$ Escola de Veterinária e Zootecnia da Universidade Federal de Goiás - UFG - Campus Samambaia. Avenida Esperança, s/n, Campus Universitário - Goiânia-GO CEP: 74.690.900. Telefone: (62) 3521-1664.

${ }^{2}$ Professor Doutor da Universidade Federal de Goiás - Regional Jataí. * E-mail: earaujo65@live.com 
das, lesões gástricas, disfunções menstruais, tratamento de afecções oftalmológicas, hepáticas e até mesmo no controle de tumores. O óleo da polpa também é usado popularmente no tratamento de bronquites, como tonificante, antioxidante e também antifúngico (ALMEIDA; SILVA, 1994; BEZERRA et al., 2002; ROESLER et al., 2007; AGRA; FREITAS; BARBOSA, 2007; ROESLER et al., 2008; LIMA, 2008; OLIVEIRA et al., 2008; QUIRINO, 2009; SOARES et al., 2010; ASCARI; TAKAHASHI, 2010).

Embora a capacidade terapêutica do pequi e seus derivados seja muito difundida no conhecimento popular, existem poucos estudos demonstrando cientificamente sua atividade biológica e seu mecanismo de ação sobre algumas afecções, assim como uma possível toxicidade que seus componentes possam apresentar (ROESLER et al., 2008).

Diante do exposto, esta revisão da literatura tem o propósito de apresentar os principais princípios ativos já identificados no Caryocar brasiliense e também o que se tem descoberto e comprovado cientificamente quanto à atividade terapêutica deste fruto, demonstrando a importância do mesmo para o desenvolvimento de possíveis terapias contra variadas doenças.

\section{Desenvolvimento}

\section{Uso das plantas medicinais}

A utilização de plantas medicinais provavelmente é tão antiga como o aparecimento da civilização humana, que procurava no reino vegetal alimentos, abrigos e meios para o alívio de suas dores e cura para seus males. O uso de ervas, extratos vegetais e derivados de produtos naturais é uma modalidade terapêutica que resistiu à passagem do tempo e acompanhou o desenvolvimento dos povos (OLIVEIRA; AKISUE, 2000; PATWARDHAN, 2005).

Os chineses, egípcios, hindus e gregos foram os primeiros a catalogar as ervas medicinais, classificando-as de acordo com a sua forma, cor, sabor e aroma, incluindo ainda ligações com os astros e, evidentemente seus atributos "mágicos". Há relatos, por exemplo, do uso de plantas com finalidades terapêuticas por volta de 3.000 a.C. na obra Pen Ts'ao do chinês Shen Nung. No ano 78 d.C., o botânico grego Pedanios Dioscorides (40-90 d.C.) realizou a primeira compilação sistemática de plantas, descrevendo 579 plantas medicinais e 4.700 usos e formas de atuação dessas plantas em uma obra de cinco volumes, intitulada De Materia Medica. Esse tratado foi de grande importância para a medicina européia até o século XVII, tendo permanecido como fonte de referência para as farmacopeias modernas (ROBBERS; SPEEDIE; TYLER, 1997; TYLER, 1996; KO, 1999; LIMA, 2006)

No Brasil, a utilização das plantas não só como alimento, mas também como fonte terapêutica teve início desde que os primeiros habitantes chegaram ao país há cerca de 12 mil anos. Esses migrantes deram origem aos paleonídeos amazônicos, dos quais derivaram as principais tribos indígenas do país (SILVA; CARVALHO, 2004).

A flora brasileira foi descoberta por cientistas estrangeiros, especialmente os naturalistas, que realizavam grandes expedições científicas no Brasil desde o descobrimento pelos portugueses até ao final do século XIX. Entre 1560 a 1580 , o Padre José de Anchieta detalhou em suas cartas aos Superiores Geral da Companhia de Jesus as plantas comestíveis e medicinais do Brasil. As plantas especificamente mencionadas foram: capim-rei, ruibarbo do brejo, ipecacuanha-preta, cabriúva-vemelha, "erva boa" e hortelã-pimenta, que eram utilizadas pelos indígenas contra indigestão, aliviando nevralgias, reumatismos, doenças nervosas, purgativos, bálsamos e cura de feridas (SILVA, 2002; SILVA; CARVALHO, 2004).

No Brasil, as plantas eram utilizadas até a metade do séc. XX na cura de inúmeras doenças. Com o advento da industrialização, da urbanização e avanço da tecnologia voltada à elaboração de fármacos sintéticos, a utilização desses medicamentos aumentou muito, principalmente na população de maior poder aquisitivo, diminuindo a utilização de plantas medicinais (TOMAZZONI; NEGRELLE; CENTA, 2006).

Após a década de 1960, observou-se um desinteresse da indústria farmacêutica e dos institutos de pesquisa pela busca de novas substâncias de origem vegetal, por se acreditar que já haviam sido isoladas as principais substâncias ativas das drogas vegetais conhecidas, bem como já haviam sido realizadas todas as possíveis modificações químicas de interesse dessas substâncias. As pesquisas com ervas medicinais foram deixadas de lado pelo grande avanço das formas sintéticas. A produção de fármacos por via de síntese química, o crescimento do poder econômico das indústrias farmacêuticas e a ausência de comprovações científicas de eficácia das substâncias de origem vegetal, aliada às dificuldades de controle químico, físico-químico, farmacológico e toxicológico dos extratos vegetais até então utilizados, impulsionaram a substituição desses por fármacos sintéticos (RATES, 2001; SCHENKEL; GOSMANN; PETROVICK, 2001; FRANCESCHINI, 2004).

Entretanto, a partir dos anos 1980, os avanços técnicos e o desenvolvimento de novos métodos de isolamento de substâncias ativas a partir de fontes naturais, permitiram maior rapidez na identificação de substâncias em amostras complexas como os extratos vegetais, ressurgindo o interesse pela pesquisa dessas substâncias como protótipos para obtenção de fármacos com atividades terapêuticas semelhantes à dos compostos originais. Tal fato é comprovado pela evidência de que hoje cerca de $25 \%$ dos fármacos prescritos no mundo são obtidos direta ou indiretamente de plantas. Além disso, cerca de $49 \%$ dos fármacos desenvolvidos entre 1981 a 2002 foram obtidos a partir de produtos naturais ou análogos semi-sintéticos ou ainda compostos sintéticos baseados em produtos naturais (ROBBERS; SPEEDIE; TYLER, 1997; KOEHN; CARTER, 2005).

$\mathrm{O}$ uso de plantas tem envolvido não somente o seu uso como tal, mas também como matéria-prima para o isolamento de compostos ativos, como a morfina, isolada do ópio ainda no início do século XIX. O isolamento dessa substância da Papaver somniferum em 1803, pelo farmacêutico Friedrich Wilhelm Adam Sertürner, marcou o início do processo de extração de princípios ativos de plantas. A partir de então, outras substâncias foram isoladas, como por exemplo a quinina, isolada em 1819 de espécies de Cinchona sp., nativa dos Andes, a atropina e escopolamina em 1831 a partir da Atropa belladona, planta da família das Solanáceas empregada pelos antigos gregos, e a reserpina, isolada de Rauwolfia 
serpentina, de uso popular na Índia (TYLER, 1996; BALUNAS; KINGHORN, 2005).

As plantas medicinais representam historicamente uma das principais e mais disseminadas fontes de medicação pela população em geral e, apesar do aumento no uso de medicamentos sintéticos nos últimos anos, seu emprego tem sido ainda o tratamento de escolha para muitas populações no mundo inteiro, sendo para algumas a única fonte de medicação. São frequentemente utilizadas com o intuito de substituir ou auxiliar as terapias convencionais no tratamento de várias doenças. No Brasil, a utilização das plantas medicinais decorre da facilidade de obtenção e do baixo custo aliada ao acesso ainda restrito da população à assistência médica e farmacêutica. Além disso, efeitos colaterais das drogas químicas motivam pessoas a utilizarem plantas medicinais (SIMÕES, 1998; SIMÕES, 2004; HALBERSTEIN, 2005; GONZALÉZ, 2006).

O mercado de plantas medicinais, como esclarece a Organização Mundial da Saúde (OMS), é de meio trilhão de dólares no mundo, e chega a movimentar no Brasil aproximadamente US\$ 260 milhões anuais. De acordo com relatório do Instituto Brasileiro do Meio Ambiente (IBAMA), em 1998 chegaram a ser exportadas 2.842 toneladas de plantas medicinais. No Brasil, os maiores exportadores são: Paraná, São Paulo, Bahia, Maranhão, Amazonas, Pará e Mato Grosso (RODRIGUES, 2004).

As vendas no setor de medicamentos fitoterápicos crescem $10 \%$ ao ano, com estimativa de terem alcançado a cifra de US\$ 550 milhões no ano de 2001. A cifra brasileira é pequena se comparada aos valores publicados para a Europa e Estados Unidos no ano de 2000, o equivalente a 8,5 e 6,3 bilhões de dólares, respectivamente. (SIMÕES; SCHENKEL, 2002; KNAPP, 2006)

Esses valores indicam um mercado em potencial expansão, principalmente se considerarmos a biodiversidade brasileira. O Brasil é um país privilegiado, pois possui a mais diversa flora, número superior a 55 mil espécies descritas, o que corresponde a $22 \%$ do total mundial. A imensa variedade de espécies de plantas, animais e microrganismos existentes no ecossistema brasileiro, sem dúvida, apresenta um importante diferencial para o desenvolvimento de medicamentos (KATO, 2001).

A OMS define planta medicinal como sendo "todo e qualquer vegetal que possui, em um ou mais órgãos, substâncias que podem ser utilizadas com fins terapêuticos ou que sejam precursores de fármacos semi-sintéticos". A diferença entre planta medicinal e fitoterápico reside na elaboração da planta para uma formulação específica, o que caracteriza um fitoterápico. Segundo a Secretaria de Vigilância Sanitária, em sua portaria $\mathrm{n}^{\mathrm{o}} 6$ de 31 de janeiro de 1995, fitoterápico é "todo medicamento tecnicamente obtido e elaborado, empregando-se exclusivamente matérias-primas vegetais com finalidade profilática, curativa ou para fins de diagnóstico, com benefício para o usuário. É caracterizado pelo conhecimento da eficácia e dos riscos do seu uso, assim como pela reprodutibilidade e constância de sua qualidade. É o produto final acabado, embalado e rotulado. Na sua preparação podem ser utilizados adjuvantes farmacêuticos permitidos na legislação vigente. Não podem estar incluídas substâncias ativas de outras origens, não sendo considerado produto fitoterápico quaisquer substâncias ativas, ainda que de origem vegetal, isoladas ou mesmo suas misturas". Nesse último caso encontra-se o fitofármaco, que por definição "é a substância ativa, isolada de matérias-primas vegetais ou mesmo, mistura de substâncias ativas de origem vegetal"(WHO, 1998; VEIGA; PINTO; MACIEL, 2005).

\section{Pesquisa fitoquímica}

A pesquisa fitoquímica tem o objetivo de conhecer os constituintes químicos presentes nas espécies vegetais, podendo ser identificados na análise fitoquímica preliminar grupos relevantes de metabólitos secundários, que constituem os princípios ativos vegetais. Dessa maneira, esses estudos fundamentam a utilização de vegetais como fonte de matéria-prima farmacêutica para a descoberta de substâncias ativas de plantas como protótipo de fármacos e também para o desenvolvimento de fitoterápicos (SIMÕES, 2004).

Os efeitos farmacológicos observados nos fitoterápicos referem-se a um único constituinte presente ou a interação de vários constituintes químicos do mesmo extrato. É então de extrema importância a análise científica para "lapidar" as substâncias naturais, aumentando as propriedades benéficas desejadas e minimizando seus possíveis efeitos tóxicos e/ou adversos (SCHENKEL et al., 2001; WAGNER; WISENAUER, 2006).

Diante desse diverso e inesgotável arsenal terapêutico presente nas plantas medicinais, as principais indústrias farmacêuticas investem cada vez mais na pesquisa envolvendo os vegetais, pois grande parte dos medicamentos existentes no mercado se originou de produtos naturais, em especial de plantas. Essas pesquisas e estudos com plantas medicinais são justificados pelo avanço do mercado de fitoterápicos que movimentou no mercado mundial aproximadamente US\$20 bilhões de dólares no ano de 2010. No Brasil, esse mercado movimentou aproximadamente US\$ 1 bilhão no ano de 2011 com estimativa de crescimento de $10 \%$ a $15 \%$ no ano de 2012 (FERREIRA, 2002).

Quando se busca obter compostos bioativos, alguns cuidados devem ser tomados em relação à seleção do material vegetal. Este deve ser corretamente colhido e classificado, sendo necessário obter informações sobre os seus possíveis efeitos tóxicos. Na etapa que determina o estudo fitoquímico, escolhe-se preliminarmente a parte da planta mais utilizada na medicina popular para ser investigada, como a raiz, cascas do caule, caule, galhos, folhas, flores e frutos. As observações populares sobre o uso e a eficácia das espécies medicinais contribuem de forma relevante para a divulgação das virtudes terapêuticas dos vegetais e auxilia os pesquisadores na seleção de espécies para estudos botânicos, farmacológicos e fitoquímicos. Sabe-se que cerca de $75 \%$ dos compostos puros naturais empregados na indústria farmacêutica foram isolados seguindo recomendações da medicina popular (SILVA; VIZZOTTO, 1996; CECHINEL; YUNES, 1998; VEIGA et al., 2002; MACIEL; PINTO; VEIGA, 2002).

Geralmente, colhe-se entre 3 a $6 \mathrm{~kg}$ do material vegetal, buscando o isolamento em grandes quantidades de substâncias majoritárias para possibilitar suas avaliações farmacológicas. O material colhido deve ser cuidadosamente separado em embalagem de sacos plásticos para ser então realizada a pesagem, armazenagem, moagem e a obtenção de extratos (VEIGA et al., 2002). 
A secagem pode ser realizada ao sol, à sombra ou em estufa, e deve ser procedida logo após a colheita para evitar a proliferação de fungos. Na preparação dos extratos, a planta deve estar completamente fresca ou totalmente seca, para definir com melhor exatidão o rendimento tanto da massa bruta como dos constituintes químicos. Caso se deseje armazenar o material vegetal, o mesmo pode ser acondicionado em freezer para prevenir oxidação, hidrólise e ataque de microorganismos (CECHINEL; YUNES, 1998; VEIGA et al., 2002).

A moagem deverá ser efetuada na ocasião da preparação dos extratos, que é feita geralmente por percolação (método de extração a frio), pois apresenta menor risco de reações químicas e de formação de artefatos decorrentes da ação combinada entre solventes e temperaturas elevadas. $\mathrm{O}$ extrato preparado é análogo às tinturas realizadas na cultura popular, onde se misturam as partes ativas das plantas com bebidas alcoólicas, sendo o metanol o solvente mais adequado para obtenção do extrato bruto, pois possibilita a extração de um maior número de compostos. Vários solventes de polaridades crescentes visando uma semi-purificação das substâncias por meio de suas polaridades, são utilizados, como o hexano, diclorometano, acetato de etila e butanol. (CIRILO, 1993; CECHINEL; YUNES, 1998; YUNES, 2001; VEIGA et al., 2002).

Existem diferentes técnicas cromatográficas às quais o extrato selecionado pode ser submetido, sendo estas técnicas baseadas em um método físico-químico de separação e estando fundamentadas na migração diferencial dos componentes de uma mistura. Podem ser utilizadas, por exemplo, a cromatografia em coluna aberta (CC), cromatografia em camada delgada (CCD), cromatografia líquida de alta eficiência (CLAE), cromatografia de dupla contra-corrente (CDCC) e cromatografia gasosa ou cromatografia gasosa acoplada ao espectrômetro de massa (VOGEL, 1988; CECHINEL; YUNES, 1998).

Quando se procura princípios ativos em plantas, devem ser levados em consideração a simplicidade, a rapidez, a reprodutibilidade e o baixo custo dos testes biológicos. A avaliação dos efeitos biológicos tanto "in vitro" como "in vivo", depende de fatores estruturais e experimentais. É necessário um biotério adequado, um laboratório para a realização dos experimentos e a escolha de modelos que possam ser reproduzidos corretamente e evitados os resultados falso-positivos. Os experimentos devem ser repetidos várias vezes para se obter dados estatísticos que comprovem a eficácia do material testado (HAMBURGER; HOSTETTMANN, 1991; CECHINEL; YUNES, 1998).

Assim sendo, as plantas medicinais, dentre elas o pequi, desempenham, portanto, papel muito importante na medicina moderna, já que podem fornecer fármacos extremamente importantes. Além disso, as fontes naturais fornecem compostos que podem ser levemente modificados, tornando-os mais eficazes ou menos tóxicos (ROBBERS; SPEEDIE; TYLER, 1997).

\section{Plantas medicinais do Cerrado}

O Brasil é o país que possui a maior diversidade biológica do planeta, abrigando aproximadamente 30\% das espécies de plantas existentes no mundo. A rica flora encon- tra-se distribuída no espaço geográfico brasileiro em seis grandes biomas: Cerrado, Campos e Florestas Meridionais, Floresta Atlântica, Caatinga, Floresta Amazônica e Pantanal (RIBEIRO; WALTER, 1998).

O bioma Cerrado é o segundo maior bioma brasileiro em área, apresentando um complexo vegetal formado por árvores, arbustos e gramíneas, localizado basicamente no Planalto Central. Originalmente com uma área de 204 milhões de hectares, aproximadamente $25 \%$ do território nacional, apresenta grande variabilidade de clima e solos e, certamente, uma grande diversificação florística em suas diferentes fisionomias vegetais (ALMEIDA et al., 1998; SANO; ALMEIDA, 1998; SILVA et al., 2001).

O Cerrado está presente nos estados de Goiás, Tocantins, Distrito Federal, Bahia, Ceará, Maranhão, Mato Grosso do Sul, Minas Gerais, Piauí, Rondônia e São Paulo. Também ocorre em áreas disjuntas ao norte dos estados do Amapá, Amazonas, Pará e Roraima. No entanto, cerca de $80 \%$ da área original já foi alterada de alguma forma, restando apenas 20\% de área natural (ALMEIDA et al., 1998; RIBEIRO; WALTER, 1998; VIEIRA; COSTA, 2007).

A riqueza vegetal do bioma Cerrado constitui-se de espécies capazes de enfrentar extensos períodos de estações de seca. Desta forma, essas plantas possuem muitas adaptações para resistir ao sol, à baixa umidade e às frequentes queimadas. Suas características morfológicas permitem o acúmulo de reservas que frequentemente possuem substâncias farmacologicamente ativas. Pode-se considerar que apenas no bioma Cerrado estejam presentes mais de 600 espécies medicinais (DEMMING; ADAMS, 1992; GUARIM; MORAES, 2003).

Os frutos das espécies nativas do Cerrado ocupam lugar de destaque, pois oferecem elevado valor nutricional, além de atrativos sensoriais como cor, sabor e aroma peculiares e intensos, ainda pouco explorados comercialmente. $\mathrm{O}$ pequi é um fruto encontrado em regiões tropicais, onde as plantas recebem alta incidência de raios solares. Influenciadas pela alta quantidade de luz e calor, a síntese e atividade de enzimas antioxidantes dessas plantas tendem a aumentar, a fim de sequestrar radicais livres. Além disso, tanto a polpa quanto a amêndoa do pequi são ricas em lipídios. Essas condições favorecem a biossíntese de compostos secundários com propriedades antioxidantes (ALMEIDA; SILVA, 1994; ALMEIDA et al., 1998; LIMA, 2008).

\section{Caracterização Botânica do Pequi (Caryocar brasiliense)}

O pequi (Caryocar brasiliense), conhecido popularmente como, piqui, pequiá, piqui-do-cerrado, piquiá-bravo, pequerim, amêndoa-de-espinho, grão-de-cavalo ou suarí, é o fruto do pequizeiro, árvore frutífera sul americana pertencente à classe Magnoliopdida (Dicotiledonae), ordem Guttiferales, família Caryocaraceae e ao gênero Caryocar L., que abrange cerca de 16 espécies, sendo 12 encontradas no território brasileiro. O nome da planta vem da palavra tupi "pyqui", onde "py" significa casca e "qui", espinhos (ALMEIDA; SILVA, 1994; ARAÚJO, 1995; OLIVEIRA et al., 2008).

Há presença marcante de C. brasiliense Camb. em todo o cerrado brasileiro, incluindo os Estados do Pará, Mato Grosso, Goiás, Distrito Federal, São Paulo, Minas Gerais e Paraná, como também nos Estados nordestinos, Piauí, Ceará 
e Maranhão ${ }^{65}$.

O pequizeiro é uma planta arbórea, atingindo entre 8 e 12 metros de altura. Apresenta tronco com circunferência de 2 a 3 metros, casca áspera, rugosa, cinza escura e fendida, com folhas verdes e flores branco-amareladas. Seus galhos são longos, grossos e ligeiramente inclinados. As folhas são compostas, trifoliadas, opostas, com limbo oval, base aguda e obtusa no folíolo central e desigual nos folíolos laterais, verdes e brilhantes, com ausência de pelos e de glândulas. Suas laterais são serreadas, denteadas ou crenadas (ALMEIDA; SILVA, 1994; OLIVEIRA et al., 2008).

O pequi é composto por exocarpo ou pericarpo (casca) bastante delgado com coloração esverdeada ou marrom-esverdeada, correspondente à menor porção do fruto. $\mathrm{O}$ mesocarpo externo é uma camada esbranquiçada bastante espessa, enquanto o mesocarpo interno ou polpa é caracterizado por ser a parte comestível do fruto, sendo uma massa amarela, farinácea, pastosa, oleosa, carnosa, aromática e rica em tanino que reveste o endocarpo e corresponde, em média, a $8,5 \%$ da massa total do fruto. O mesocarpo interno está intimamente aderido ao endocarpo, constituindo um único segmento (VERA, 2005; LIMA, 2008; ASCARI; TAKAHASHI, 2009).

$\mathrm{O}$ endocarpo lenhoso, recoberto com alta densidade de espinhos delgados, rígidos com 2 a $5 \mathrm{~mm}$ de comprimento e avermelhados, protege a semente ou amêndoa (MELO, et al. 2004).

Em cada planta podem-se encontrar entre 500 e dois mil frutos. Eles apresentam de seis a $14 \mathrm{~cm}$ de comprimento por seis a dez $\mathrm{cm}$ de diâmetro. $\mathrm{O}$ peso por unidade varia de 100 a 300 gramas. O número de sementes varia de um a quatro por fruto e são oleaginosas de cor branca (amêndoa) e se apresentam em forma de um pequeno rim (ALMEIDA; SILVA, 1994).

Sua florescência ocorre durante os meses de agosto a novembro, com a maturação dos frutos em meados de novembro, porém o pico é durante os meses de dezembro e janeiro, podendo ser encontrados até fevereiro (ALMEIDA et al., 1998; LORENZI, 2002).

\section{Metabólitos secundários}

A vida dos organismos vivos depende das transformações químicas executadas pelos seus metabolismos primários e secundários. Como as plantas são incapazes de se locomover para escapar dos herbívoros, tiveram que desenvolver técnicas para minimizar sua predação, criando estratégias variadas de defesa e repulsão de seus predadores. Um importante meio de defesa são metabólitos secundários, que geralmente são concentradas nas partes da planta que mais contribuem para o crescimento e propagação como folhas novas, ramos de florescência e sementes (BRAZ-FILHO, 1994; STILING, 1996; RALPHS; GARDNER; PFISTER, 2000; BARBOSA; RIBEIRO FILHO, 2007).

Esses constituintes bioquímicos produzidos pelo metabolismo secundário dos organismos vivos, como os compostos terpenos, alcaloides, glicosídios e vários outros, apresentam atividades biológicas que cujo mecanismo de ação deve ser objeto investigação farmacológica (BRAZ-FILHO, 1994).

Alterações qualitativas e/ou quantitativas de me- tabólitos secundários em pesquisa realizadas com a mesma espécie vegetal podem ocorrer, considerando que a síntese de tais constituintes é resultante da interação da planta com o ambiente, sofrendo influência do local da colheita, clima, sazonalidade, índice pluviométrico, fertilidade do solo, umidade, temperatura, altitude, idade da planta, época de coleta, radiação ultravioleta, nutrientes, poluição atmosférica e ação de patógenos (MACIEL; PINTO; VEIGA, 2002).

\section{Princípios ativos do pequi}

Os metabólitos secundários encontrados na prospeç̧ão fitoquímica das folhas de C. brasiliense no estudo realizado por Dias (2011) constituem-se de esteróides, triterpenóides, heterosídeos cardiotônicos, heterosídeos flavonoides, taninos, alcaloides e cumarinas. Marques (2000), em análises fitoquímicas preliminares também das folhas e do botão floral desse vegetal, indicaram a presença de taninos, flavonoides, esteroides, triterpenoides e saponinas. Já Oliveira (1968) detectaram esteróides e triterpenoides no estudo fitoquímico das folhas de $C$. brasiliense. O estudo realizado por Magalhães (1988) revelou a presença de taninos, saponinas, flavonoides e heterosídeos antociânicos nas folhas desta espécie.

Foi realizada também a prospecção fitoquímica do extrato hidroetanólico das folhas de pequi por Ribeiro (2009), que verificaram a presença de flavonoides, saponinas, taninos e glicosídeos cardiotônicos, bem como a ausência de alcaloides e glicosídeos antraquinônicos neste extrato. Da mesma forma, Paula-Junior (2004) ao realizar a abordagem fitoquímica do pequi, verificou também presença de flavonoides e saponinas, além de óleos essenciais, taninos condensados e hidrolisáveis.

BEZERRA et al. (2002) detectaram, no extrato etanólico das folhas e das cascas de pequi, a presença de taninos condensados, taninos hidrolisáveis, flavonoides e terpenos e no extrato das folhas, a presença de terpenos.

Os heterosídeos cardiotônicos são metabólitos recomendados para o tratamento de insuficiência cardíaca congestiva (ICC) e tratamento de choque cardiogênico no caso de edema pulmonar. Eles possuem também uma alta toxicidade e um alto índice de reações adversas, isso ocorre principalmente porque a concentração capaz de causar efeitos tóxicos é apenas duas vezes superior à concentração terapêutica (RATES; BRIGI, 2007).

Nas folhas de Caryocar brasiliense há elevada quantidade de compostos fenólicos, dentre eles os flavonoides, que apresentam grande interesse farmacológico. Já foram atribuídas propriedades antiespasmódica, antinflamatória, antialérgica, antiulcerogênica, antiviral, dentre outras a diversos flavonoides. É dedicada atenção especial aos produtos que possam agir como antioxidantes, ou seja, que combatam o estresse oxidativo, coadjuvante no tratamento de diversas doenças infecciosas e/ou inflamatórias. Nesse contexto, os compostos fenólicos presentes na folha do pequi são incluídos na categoria de bloqueadores de radicais livres, sendo normalmente empregados como anti-oxidantes, podendo ser efetivos em reduzir danos oxidativos nos seres humanos, os quais estão envolvidos na gênese e/ou desenvolvimento de várias doenças via estresse oxidativo. Lima et al. (2007) associaram a elevada concentração de compostos 
fenólicos do pequi, ao fato do fruto ser encontrado em regiões onde as árvores recebem alta incidência de raios solares favorecendo a geração de radicais livres (SHAHIDI; JANITHA; WANASUNDARA, 1992; PAULA-JÚNIOR, 2004; VALIM et al., 2007).

Em estudos realizados por Miranda-Vilela (2009) no óleo extraído da polpa, também foram encontrados anti-oxidantes naturais. O teor de óleos e compostos antioxidantes da amêndoa, da polpa e das flores do pequi tornam essas partes da planta interessantes para o uso nas indústrias farmacêuticas e de cosméticos. O óleo extraído das sementes apresenta um odor suave e textura agradável, sendo principalmente utilizado na produção de sabonetes e emulsões com finalidades estéticas, como cremes e loções (ARAÚJO, 2000).

Roesler et al. (2007) também verificaram atividade antioxidante do pequi, e dentre os compostos bioativos encontrados em sua polpa, foi identificado o flavonoide quercetina, um importante antioxidante natural. Estes resultados indicam que a polpa do pequi é um alimento com elevada capacidade antioxidante, demonstrando a correlação existente entre a quantidade de compostos fenólicos totais e a proteção antioxidante (KUSKOSKI et al., 2005).

O extrato aquoso da polpa do pequi também foi avaliado por Khouri et al. (2007) em relação a eficácia contra mutagenicidade induzida por ciclofosfamida e bleomicina. Os resultados foram sugestivos de que o potencial antimutagênico observado ocorreu possivelmente devido às propriedades antioxidantes do pequi.

O teor de compostos fenólicos totais na polpa do pequi é de $209 \mathrm{mg} / 100 \mathrm{~g}$, proporção mais elevada do que as encontradas na maioria das polpas frutas consumidas no Brasil, como Açaí (Euterpe oleracea) com 136,8mg/100g; goiaba (Psidium guayava), com 83,1mg/100g; abacaxi (Ananas sativa), com 21,7mg/100g; graviola (Anona muricato), com $84,3 \mathrm{mg} / 100 \mathrm{~g}$, e maracujá (Passiflora edulis), com 20,2 mg/100g, sendo inferior apenas à acerola (Malpighia glabra), com 580,1mg/100g, e à manga (Mangifera indica), com 544mg/100g (CREPALDI et al., 2001).

Perez (2004) encontrou flavonoides no mesocarpo interno, endocarpo e exocarpo no fruto de pequi. Em estudos realizados por Crepaldi et al. (2001) na amêndoa do pequi, foram detectados um teor reduzido de compostos fenólicos e de carotenoides. Esses valores estão próximos aos de outras amêndoas típicas do cerrado brasileiro, como o baru (Dipteryx alata), a bocaiúva (Calophyllum brasiliense) e o caju (Anarcadium occidentale). Na amêndoa do pequi, o teor de compostos fenólicos totais é de $122 \mathrm{mg} / 100 \mathrm{~g}$ (CREPALDI et al., 2001; LIMA, 2008).

Outro grupo de metabólitos encontrados nas folhas de $C$. brasiliense são os taninos. Os estudos realizados com as folhas e caules do pequi revelaram a presença de taninos condensados e hidrolisáveis (BEZERRA et al., 2002). Herzog-Soares et al. (2002) e Perez (2004) também encontram taninos no extrato das cascas do fruto e no próprio fruto desta espécie.

Como metabólitos secundários, os taninos são compostos fenólicos de grande interesse econômico. A ingestão de dietas ricas em frutas que contêm taninos tem sido associada com atividade anticarcinogênica. Ademais, os taninos são hemostáticos e, como precipitam alcaloides, pode servir de antídoto em casos de intoxicações (BRUNETON, 1991;

\section{CHUNG; JOHNSON, 1998).}

Além disso, os taninos podem agir como antiinflamatórios e cicatrizantes. Segundo Batista (2010) os taninos estão presentes no óleo de pequi, o que lhe confere uma atividade cicatrizante de feridas. Os taninos possuem a capacidade de precipitar proteínas e de sequestrar íons metálicos, principalmente o ferro, essencial ao desenvolvimento de micro-organismos, propiciando um efeito antimicrobiano e antifúngico. Ainda, os taninos possuem elevada atividade antioxidante decorrente da inativação de radicais livres (MELLO et al., 2001; HERZOG-SOARES et al., 2002; BATISTA, 2010).

Foram encontradas cumarinas nas folhas de $C$. brasiliense no estudo fitoquímico realizado por Dias et al. (2011). É atribuída uma grande variedade de atividades biológicas às cumarinas, como a ação antimicrobiana, antiviral, anti-inflamatória, antiespasmódica, antitumoral e antioxidante (DIAS; MORAES, 2011; MAGID et al., 2006).

Foi identificada também a presença de alcaloides em amostras de folhas de C. brasiliense. Sabe-se que os alcaloides são exemplos de metabólicos secundários que originaram diversos fármacos, sendo que sua diversidade estrutural e variadas atividades farmacológicas fazem desses metabólitos um dos grupos mais importantes entre as substâncias naturais com interesse terapêutico. Os alcaloides apresentam sempre ação farmacológica ou tóxica quando administrados em animais. Essa classe de substâncias do metabolismo secundário é famosa pela acentuada ação sobre o sistema nervoso central, sendo muitos deles utilizados como venenos ou alucinógenos (BARREIRO; FRAGA, 2001; CORDELL; QUINN-BEATTI; FARNSWORTH, 2001; HENRIQUES; KERBER, 2001; LUCA; PIERRE, 2005; DIAS; MORAIS, 2011).

Os esteroides também foram compostos químicos encontrados nas folhas de C. brasiliense no estudo fitoquímico realizado por Dias e Morais (2011). As plantas ricas em esteroides despertam o interesse de indústrias farmacêuticas, pois estas substâncias podem representar moléculas de partida para a obtenção semi-sintética de fármacos esteroidais, como anticoncepcionais, anti-inflamatórios esteroidais e anabolizantes (OLIVEIRA, 2007; DIAS; MORAIS, 2011).

Houve registro da presença de saponinas nas folhas de C. brasiliense. As principais ações farmacológicas de plantas que apresentam saponinas são anti-inflamatória, larvicida, hipocolesterolemiante, expectorante, ventrópica, moluscicida e cicatrizante. Estudos têm comprovado a ação moluscicida de metabólitos secundários, sendo as saponinas, juntamente com os terpenoides, os esteroides e os flavonoides os principais agentes moluscicidas (CANTANHEDE, 2000; PELAH; ABRAMOVICH; WIESMAN, 2002; JANEWAY et al., 2006).

\section{Aspectos terapêuticos do pequi}

O homem busca na natureza produtos que atuem no combate a doenças infecciosas, inflamatórias e também produtos que possam agir como antioxidantes. Assim, o pequi tem ganhado a atenção de pesquisadores devido às atividades terapêuticas antibacteriana, antifúngica, parasiticida e antioxidante apresentadas (PASSOS et al. 2001; PAULA-JÚNIOR, 2004; PAULA-JUNIOR et al. 2006; LU et al., 2007). 
O fruto pequi possui cerca de $33 \%$ de lipídeos, majoritariamente ácido oleico, que é um ácido graxo insaturado essencial para o organismo animal. Dentre os estudos realizados destaca-se o efeito antitumoral, observado por Oliveira et al. (1968), que avaliaram o efeito deste ácido, isolado do extrato etanólico das folhas do pequi sobre camundongos portadores do sarcoma 180 na forma sólida e observaram que este composto demonstrou efeito inibidor (entre 15 a $67 \%$ ) sobre o desenvolvimento do tumor, podendo esse, ter propriedades antitumorais (OLIVEIRA; GILBERT; MORS, 1968; ALMEIDA; SILVA, 1994).

O pequi também tem sido relatado por possuir atividade antifúngica. Passos et al.(2001) avaliaram a atividade antifúngica do pequi sobre Cryptococus neoformans var. neoformans e, constataram que todas as partes do fruto apresentavam atividade antifúngica, sendo que a cera retirada das folhas apresentavam atividades mais elevada, inibindo o crescimento de $91,3 \%$ dos isolados do microorganismo. Marques et al. (2002) observaram que extratos metanólicos e etanólicos de folhas, botões florais, frutos (mesocarpo externo, mesocarpo interno e amêndoa) também têm efeito tóxico na germinação de esporos de Botrytis cinerea, Colletotrichum truncatum e Fusarium oxysporum.

Bezerra et al. (2002) verificaram que o extrato etanólico de folhas e das cascas do pequi, na concentração de 100 ppm, têm atividade moluscicida contra Biomphalaria glabrata, pois observou-se a morte de $90 \%$ da população do hospedeiro intermediário do Schistosoma mansoni.

Um estudo realizado por Herzog-Soares et al. (2002) avaliou o efeito do extrato bruto etanólico da casca do pequi (400 ppm) em camundongos infectados, via intraperitoneal, com formas tripomastigotas do Trypanosoma Cruzi, sendo observado uma significativa interferência sobre a curva de parasitemia, frente ao grupo controle, com reduzido número de parasitos no sangue.

Alguns trabalhos in vitro demonstram que taninos condensados presentes na casca do fruto de pequi apresentam ação nematicida ao reduzirem a eclosão e o desenvolvimento de nematoides parasitas de ruminantes (ICBAL, et al. 2007).

No trabalho de Paula-Júnior (2004) foi observado que o extrato das folhas de C. brasiliense Cambess apresenta ação antimicrobiana contra cepas de Enterococcus faecalis, Escherichia coli, Pseudomonas aeruginosa e Staphylococcus aureus, avaliada pelo método de difusão em ágar.

Paula-Junior (2006) também demonstraram a capacidade do extrato hidroetanólico das folhas de pequi, nas concentrações de 2,5 e $5,0 \mathrm{mg} / \mathrm{ml}$, de inibir a proliferação de formas promastigotas de Leishmania amazonensis in vitro. Esse efeito foi superior aos efeitos do antimoniato de meglumina (Glucantime), droga de escolha para o tratamento da leishmaniose. Cardoso (2001) tratou grupos de camundongos com extrato bruto das folhas de $C$. brasiliense contra proliferação de L. amazonensis, observando que apesar de não terem adiado o desenvolvimento das lesões, estas mantiveram-se menores comparadas ao grupo controle.

Miguel (2011) avaliou a ação neuroprotetora do extrato etanólico da casca de pequi em cérebros de ratos submetidos à isquemia e reperfusão. Observou-se que o extrato etanólico da casca de pequi nas concentrações de $300 \mathrm{mg} / \mathrm{Kg}$ e $600 \mathrm{mg} / \mathrm{kg}$ apresentou uma possível atividade neuroprotetora, devido à redução do número de neurônios isquêmicos, na região do córtex frontal.

\section{Conclusão}

O uso das plantas para fins terapêuticos acompanha o homem há milhares de anos, propagado com base em observações dos resultados obtidos desse uso. Apesar da importância inquestionável do uso das plantas medicinais, ainda há desconhecimento com relação a real eficácia terapêutica de muitas dessas plantas, sendo necessário o respaldo científico para certificar o seu uso, mesmo as que são conhecidas por sua aplicação milenar.

Estudos visando o conhecimento científico das plantas medicinais crescem anualmente no Brasil e no mundo. Junto com esses estudos, além da descoberta de novas substâncias úteis para a saúde e bem-estar do homem, aumenta o interesse e o conhecimento sobre os componentes químicos das plantas. O bioma Cerrado apresenta uma grande biodiversidade, e sua flora é fonte de substâncias biologicamente ativas, ainda não totalmente exploradas.

O pequi, natural do Cerrado, tem sido alvo de várias pesquisas devido aos diversos componentes químicos que essa espécie apresenta, tais como os compostos fenólicos, conhecidos farmacologicamente por seu potencial antioxidante, além de esteroides, heterosídeos e alcaloides. As análises fitoquímicas do extrato desse fruto permitem o conhecimento de informações relevantes à cerca da presença desses metabólitos secundários, possibilitando o isolamento de princípios ativos importantes na produção de novos fitoterápicos e o conhecimento de seus efeitos in vitro e in vivo.

A ação coordenada de pesquisadores de várias áreas do conhecimento, como agronomia, etnobotânica, química, farmácia, medicina, biologia e tantos outros é muito importante, pois possibilita que as informações se completem, ampliando o conhecimento sobre os efeitos terapêuticos, tóxicos e colaterais do Caryocar brasiliense baseado em estudos científicos. Assim, a população poderá utilizar esta planta medicinal de forma segura e eficaz.

\section{Referências}

AGRA, M. F.; FREITAS, P. F.; BARBOSA, J. M. F.

Synopsis of the plants known as medicinal and poisonous in Northeast of Brazil. Braz. J. Pharmacog. v. 17, n.1, p. 114-140, 2007.

ALMEIDA, S. P.; SILVA, J. A. Piqui e buriti: importância alimentar para a população dos cerrados. Planaltina: EMBRAPA-CPAC, 1994. 38 p.

ALMEIDA, S. P. et al. Cerrado: espécies vegetais úteis. Planaltina: EMBRAPA-CPAC, 1998. 464 p.

\section{ARAÚJO, F. D. A review of Caryocar brasiliense} (Caryocaraceae) - an economically valuable species of the central Brazilian cerrados. Econ Bot. v. 9, n.1, p. 40-48, 1995.

ARAÚJO, G. Vida alternativa: Fitoterapia médica. Disponível em: $<$ http://correiowebsaudeplena.com.br/ noticias/index_html?opcao=072705-04. Acesso em: $23 \mathrm{dez}$. 
2008.

ASCARI, J.; TAKAHASHI, J. A.; BOAVENTURA, M. A. D. Phytochemical and biological investigations of Caryocar brasiliense Camb. Blacpma. v. 9, n. 1, p. 20-28, 2010.

BALUNAS, M. J.; KINGHORN, D. Drug discovery from medicinal plants. Life Sci. v. 78, n.1, p. 431-441, 2005.

BARBOSA, M. A. et al. Terapias alternativas de saúde $\mathbf{x}$ alopatia: tendências entre acadêmicos de medicina. REE, v. 3, n. 2. Disponível em: <http://www.revistas.ufg.br/index. php/fen>. 2001.

BARBOSA, R. R.; RIBEIRO FILHO, M. R.; SILVA, I. P. Poisonous plants to livestock: importance and methods for study. Acta Vet. Brasílica, v. 1, n.1, p. 1-7, 2007.

BATISTA, J. S. Avaliação da atividade cicatrizante do óleo de pequi (Caryocar coriaceum Wittm) em feridas cutâneas produzidas experimentalmente em ratos. Arq. Inst. Biol. v. 77, n. 3, p. 441-447, 2010.

BARREIRO, E. J.; FRAGA, C. A. M. Química medicinal: as bases moleculares da ação dos fármacos. Porto Alegre: Artmed, 2001. 243 p.

BEZERRA, J. C. B. et al. Molluscicidal activity against Biomphalaria glabrata of Brazilian Cerrado medicinal plants. Fitoterapia, v. 73, n. 5, p. 428-430, 2002.

BRAZ, R. F. Química de produtos naturais: importância, interdisciplinaridade, dificuldades e perspectivas. A peregrinação de Pacatupano. Quim. Nova. v. 17, n. 5, p, $1-5,1994$.

BRUNETON, J. Elementos de fitoquímica y de farmacognosia. Zaragoza: Acribia, 1991. p. 189-213.

CARLINI, E. A. et al. Toxicologia pré - clínica da espinheira - santa (Maytenus ilicifolia): estudo de ação antiúlcera gástrica de plantas brasileiras (Maytenus ilicifolia e outras). Brasília: CEME, 1988.

CANTANHEDE, S. P. D. Atividade moluscicida de plantas: uma alternativa profilática. Rev Bras Farm. v. 20, n. 2, p. 282-288, 2000.

CARDOSO, L. Leishmaniose cutânea: influência da casca e folha do Caryocar brasiliense Cambess no curso da infecção Monografia. 2001. ...f. Trabalho de Conclusão de Curso. (Especialização) - Universidade Estadual de Montes Claros, Departamento de Biologia Geral, Universidade Estadual de Montes Claros, Montes Claros, 2001.

CECHINEL, F. V.; YUNES, R. A. Estratégias para a obtenção de compostos farmacologicamente ativos a partir de plantas medicinais. Conceitos sobre modificação estrutural para otimização da atividade. Quim Nova. v. 21, n.1, p. 99, 1998.
CIRILO, V. K. Manual de plantas medicinais. Francisco Beltrão: Assessoar, 1993. 12 p.

CREPALDI, I. C. et al. Composição nutricional do fruto de licuri (Syagrus coronata Martius Beccari). Rev Bras Bot. v. 24, n. 2, p. 155-159, 2001.

CHUNG, K, W. E. I. C.; JOHNSON, M. G. Are tannins a double-edged sword in biology and healt. Trends Food Sci Technol. v. 9, n. 4, p. 168-175, 1998.

CORDELL, G. A.; QUINN-BEATTI, M. L.; FARNSWORTH, N. R. The potential of alkaloids in drug discovery. Phytother Res. v.15, n.1, p. 183-205, 2001.

DEMMING, A. B.; ADAMS, W. W. Photoprotection and other response of plants to high light stress. Annu Rev Plant Physiol Plant Mol Biol. v. 43, n.1, p. 599-626, 1992.

DIAS, A. M.; MORAIS, M. C. Estudo morfoanatômico e prospecção fitoquímica das folhas de Caryocar brasiliense Cambess (Caryocaraceae) ocorrentes na base área de Anápolis - GO. 2011. ... f. Trabalho de Conclusão de Curso (Especialização) - Universidade Estadual de Goiás, Anápolis, 2011.

FERREIRA, S. H. Peripheral analgesic sites of action of anti-inflammatory drugs. Int J Clin Pract. v. 128, n.1, p. 2-10, 2002.

FRANCESCHINI, F. S. Plantas terapêuticas. São Paulo: Andrei, 2004. 334 p.

GONZALÉZ, J. Y. Uso tradicional de plantas medicinales em la Vereda San Isidro, Muncipio de San José de Pare Boyacá: um estudio preliminar usando tecnicas quantitativas. Acta Biolo Colom. v. 11, n. 1, p. 1-10, 2006.

GOSMANN, G. et al. Farmacognosia: da planta ao medicamento. 5. ed. Porto Alegre: UFRGS, p. 371-400, 2004.

GUARIM, G. N.; MORAIS, R. G. Recursos medicinais de espécies do cerrado de Mato Grosso: Um estudo bibliográfico. Acta Bot Brasilica, v. 17, n. 4, p. 561-584, 2003.

GUERRA, P. M.; NODARI, O. R. Biodiversidade: aspectos biológicos, geográficos, legais e éticos. In: SIMÕES, C. M. O. et al. Farmacognosia: da planta ao medicamento. 3. ed. Porto Alegre; Florianópolis: UFRGS; UFSC, 2001. p. 13-26.

GURIB-FAKIM, A. Medicinal plants: traditions of yesterday and drugs of tomorrow. Mol Aspects Med. v. 27, n. 1, p. 1-93, 2006.

HALBERSTEIN, R. A. Medicinal Plants: historical and cross-cultural usage patterns. Ann Epidemiol. v. 15, n.1, p. 686-699, 2005. 
HAMBURGER, M.; HOSTETTMANN, K. Bioactivity in plants: The link between phytochemistry and medicine. Phytochemistry, v. 30, n.12, p. 3864-3874, 1991.

HENRIQUES, A. T.; KERBER, V. A. Alcalóides: generalidades e aspectos básicos. In: SIMÕES, C. M. O. et al. Farmacognosia da planta ao medicamento. 3. ed. Porto Alegre: UFRGS, 2001. p. 651-666.

HERZOG-SOARES, J. D. et al. Atividade tripanocida in vivo de Stryphnodendron adstringens (barbatimão verdadeiro) e Caryocar brasiliense (pequi). Rev Bras de Farmacogn. v. 12, n.1, p. 1-2, 2002.

ICBAL, Z. et al. Direct and indirect anthelmintic effects of condensed tannins in sheep. Vet. Parasitol. v. 144, n.1, p. 125-131, 2007.

JANEWAY, C. A. et al. Imunobiologia: o sistema imune na saúde e na doença. 6. ed. Porto Alegre: Artmed, 2006. 824 p.

KATO, M. J. Global phytochemistry: the Brazilian approach. Phytochemistry. v. 57, n.1, p. 621-23, 2001.

KOEHN, F. E.; CARTER, G. T. The evolving role of natural products in drug discovery. Nat Rev Drug Discov. v. 4, n. 3, p. 206-220, 2005.

KHOURI, J. et al. Anticlastogenic potential and antioxidant effects of an aqueous extract of pulp from pequi tree (Caryocar brasiliense Camb). Genet Mol Biol. v. 30, n. 1, p. 442-448, 2007.

KNAPP, L. Fitoterapia abre novos campos de pesquisa. São Paulo: Gazeta Mercantil, 2006. p. 6.

KO, R. J. Causes, epidemiology, and clinical evaluation of suspected herbal poisoning. Clin Toxicol. v. 37, n. 6, p. 697-708, 1999.

KUSKOSKI, E. M. et al. Aplicação de diversos métodos químicos para determinar atividade antioxidante em polpa de frutos. Ciênc. Tecnol. Aliment. v. 25, n. 4, p. 726-732, 2005 .

LIMA, A. et al. Composição química e compostos bioativos presentes na polpa e na amêndoa do pequi (Caryocar coriaceum, Camb). Rev. Bras. Frutic. v. 29, n. 3, p. 695698, 2007.

LIMA, A. Caracterização química, avaliação da atividade antioxidante in vitro e in vivo, e identificação dos compostos fenólicos presentes no pequi (Caryocar brasiliense Camb.) 2008. ... f. Tese (Doutorado) Faculdade de Ciências Farmacêuticas, Universidade de São Paulo, São Paulo, 2008.

LIMA, L. Fitoterápicos e usos de plantas medicinais. Jornal da Unesp, ano 16, v. 166. Disponível em: <http:// www.unesp.br/aci/jornal/166/farmacologia.htm>. Acesso em: 5 nov. 2006.

LORENZI, H. Árvores brasileiras: manual de identificação e cultivo de plantas arbóreas nativas do Brasil. Nova Odessa: Instituto Plantarum, 2002. p. 368.

LUCA, V.; PIERRE, B. S. The cell and developmental biology of alkaloid biosynthesis. Trends Plant Sci. v. 5, n. 1, p. 168-173, 2000.

LU, Y. et al. Composition and antimicrobial activity of the essential oil of Actinidia macrosperma from China. NatProd Res. v. 21, n.1, p. 227-233, 2007.

MACIEL, M. A. M.; PINTO, A. C.; VEIGA, J. R. V. F. Plantas medicinais: a necessidade de estudos multidisciplinares. Quim Nova, v. 25, n.1, p. 429-438, 2002.

MAGID, A. et al. Triterpenoid saponins from the fruit of Caryocar glabrum. J. Nat. Prod. v. 69, n.1, p.196-205, 2006.

MAGALHÃES, H. G. Estudo estrutural do pequizeiro Caryocar brasiliense Camb. Caryocaraceae, sob o aspecto farmacoquímico e botânico. Rev Bras Farmv. v. 69, n. 3, p. 31-41, 1988.

MARQUES, M. C. S.; CARDOSO, M. G.; GAVILANES, M. L. Análise fitoquímica das folhas e botões florais do Caryocar brasiliense Camb. In: SEMINÁRIO DO CENTRO OESTE DE PLANTAS MEDICINAIS, 1., 2000, Rio Verde. Anais... Rio Verde: FESURU, 2000.

MARQUES, M. C. S. et al. Efeito fungitóxico dos extratos de Caryocar brasiliense Camb. sobre os fungos Botrytis cinerea, Colletotrichum truncatum e Fusarium oxysporum. Ciênc. Agrotec. p. 1410-1419, 2002.

MELLO, J. P. C. et al. Farmacognosia: da planta ao medicamento. 3. ed. Porto Alegre: UFSC, 2001.

MELO, A. F. J. et al. Estrutura genética de populações naturais de pequizeiro (Caryocar brasiliense Camb.). Sci. For. v. 66, n. 1, p. 56-65, 2004.

MIGUEL, M. P. Ação neuroprotetora do extrato etanólico da casca de pequi em cérebros de ratos submetidos à isquemia e reperfusão. 2011. ... f. Tese (Doutorado) - Escola de Veterinária e Zootecnia, Universidade Federal de Goiás, Goiânia, 2011.

MIRANDA-VILELA, A. L. Avaliação dos efeitos antigenotóxicos, antioxidantes e farmacológicos do extrato da polpa do fruto do pequi (Caryocar brasiliense Camb.) 2009. ... f. Tese (Doutorado) - Instituto de Ciências Biológicas, Universidade de Brasília, Brasília, 2009.

MOLL, M. C. N. Antihiperlipemiantes de origem vegetal. RDF, v. 6, n.1, p. 11-26, 2006. 
OLIVEIRA, B. H. Obtenção de novos fármacos através de biotransformação de produtos naturais. In: YUNES, R. A.; CHECHINEL-FILHO, V. Química de produtos naturais, novos fármacos e a moderna farmacognosia. Itajaí: UNIVALE, 2007.

OLIVEIRA, F.; AKISUE, G. Fundamentos de farmacobotânica. São Paulo: Atheneu, 178 p. 2000.

OLIVEIRA, M. E. B. et al. Aspectos agronômicos e de qualidade do pequi. Fortaleza: Embrapa Agroindústria Tropical, 2008. 32 p.

OLIVEIRA, M. M.; GILBERT, B.; MORS, W. B. Triterpenes in Caryocar brasiliense. In: ANAIS DA ACADEMIA BRASILEIRA DE CIÊNCIAS, 1968, Rio de Janeiro. Anais... Rio de Janeiro: academia, 1968. p. 451452.

PAULA-JÚNIOR, W. Atividades biológicas in vitro de extratos hidroetanólicos de folhas e do mesocarpo interno de Caryocar brasiliense Cambess. 2004. ... f. Dissertação (Mestrado) - Universidade Federal do Paraná, Curitiba, 2004.

PAULA-JUNIOR, W. et al. Atividades leishmanicida, bactericida e antioxidante do extrato hidroetanólico das folhas de Caryocar brasiliense Cambess. Rev Bras Farmacogn. v. 16, n.1, p. 625-630, 2006.

PASSOS, X. S. et al. Antifungal activity of Caryocar brasiliense against Paracoccidioides brasiliensis and Histoplasma capsulatum. In: CONGRESSO BRASILEIRO DE MICROBIOLOGIA, 21., 2001, Foz do Iguaçu. Anais... Foz do Iguaçu: Brasil, 2001. p. 70-71.

PATWARDHAN, B. Ethnopharmacology and drug Discovery. J. Ethnopharmacol. v. 100, p. 50-52, 2005.

PORTO, C. S. Potencial antioxidante de extratos obtidos a partir de frutos e folhas do pequi (Caryocar brasiliense Camb.). 2008. ... f. Dissertação (Mestrado) - Universidade Estadual de Montes Claros, Montes Claros, 2008.

PELAH, D.; ABRAMOVICH, Z.; WIESMAN, M. K. The use of commercial saponin from Quillaga saponaria bark as a natural larvicidal agent against Aedes aegypti and Culex pipiens. J. Ethnopharmacol. v. 81, n.1, p. 407-409, 2002.

PEREZ, E. Diagnose fitoquímica dos frutos de Caryocar brasiliense camb., caryocaraceae. 2004. ... f. Dissertação (Mestrado) - Universidade Federal do Paraná, Curitiba, 2004.

QUIRINO, G. S. Healing potential of Pequi (Caryocar coriaceum Wittm, ) fruit pulp oil. Phytochem Lett. v. 2, n.1, p. 179-183, 2009.

RAHMAN, S. Z.; SINGHAL, K. C.; Problems in pharmocovigilance of medicinal products of herbal origin and means to minimize them. Am J Health Syst Pharm. v.
59, n.1, p. 339-347, 2002.

RALPHS, M. H.; GARDNER, D. R.; PFISTER, J. A. A functional explanation for patterns of norditerpenoid alkaloid levels in tall larkspur (Delphinium barbeyi). J. Chem. Ecol. v. 26, n.1, p. 1595-1607, 2000.

RATES, S. M. K. Plants as source of drugs. Toxicon. v. 39, p. 603-613, 2001.

RATES, S. M. K.; BRIGI, R. Heterosídeos cardiotônicos. In: SIMÕES, C. M. O. Farmacognosia: da planta ao medicamento. 6. ed. Florianópolis: UFSC; Porto Alegre: UFRGS, 2007. p. 685-710.

RIBEIRO, D. S.; FERREIRA, A. A. Prospecção fitoquímica do extrato hidroetanólico de folhas de Caryocar brasiliense CAMBESS. In: FÓRUM GESTÃO/PESQUISA/ENSINO/ EXTENSÃO, 3., 2009, Montes Claros. Anais... Montes Claros, 2009.

RIBEIRO, J. F.; WALTER, B. M. T. Fitofisionomias do bioma cerrado. In: SANO S. M.; ALMEIDA, S. P. Cerrado: ambiente e flora. Planaltina: EMBRAPACPAC, 1998. p. 89-152.

RIBEIRO, R. F. Pequi: o rei do cerrado. Belo Horizonte: Rede Cerrado, 2000. 62 p.

ROBBERS, J. E.; SPEEDIE, M. K.; TYLER, V. E. Farmacognosia e farmacobiotecnologia. São Paulo: Premier, 1997. 372 p.

RODRIGUES, D. R. G. Plantas medicinais brasileiras ameaçadas de extinção. Viçosa: Imprensa Universitária, 2004. p. 17-19.

ROESLER, R. et al. Atividade antioxidante de frutas do cerrado. Ciênc. Tecnol. Aliment. v. 27, n.1, p. 53-60, 2007.

ROESLER, R. et al. Antioxidant activity of Caryocar brasiliense (pequi) and characterization of components by electrospray ionization mass spectrometry. Food Chem. v. 110, n. 1, p. 711-717, 2008.

SANO, S. M.; ALMEIDA, S. P. Cerrado: ambiente e flora. Planaltina: EMBRAPACPAC, 1998. 556 p.

SCHENKEL, E. P.; GOSMANN, G.; PETROVICK, P. Produtos de origem vegetal e o desenvolvimento de medicamentos. In: SIMÕES, C. M. O. et al. Rational phytotherapy: a physician's guide to herbal medicine. 4. ed. New York: Springer Verlag, 2001. p. 1-39.

SHAHIDI, F.; JANITHA, P. K.; WANASUNDARA, P. D. Phenolic antioxidants. Crit Rev. Food Sci. Nutr. v. 32, n.1, p. 67-103, 1992.

SILVA, A. A. J.; VIZZOTTO, V. J. Plantas medicinais, aromáticas e fitoprotetoras. RAC, v. 9, n.1, p. 5-8, 1996. 
SILVA, D. B. et al. Frutas do Cerrado. Planaltina: Embrapa Cerrados, 2001. 178 p.

SILVA, M. C.; CARVALHO, J. C. T. Plantas medicinais. In: CARVALHO, J. C. T. Fitoterápicos antiinflamatórios: aspectos químicos, farmacológicos e aplicações terapêuticas. São Paulo: Tecmed, p. 39-41, 2004.

SILVA, M. V. Plantas medicinais e tóxicas da reserva biológica do Lami. RBB, v. 57, n.1, p. 61-73. 2002.

SIMÕES, C. M. O. Farmacognosia: da planta ao medicamento. 5. ed. Porto Alegre: UFRGS, 2004.

SIMÕES, C. M. O. et al. Plantas da medicina popular do Rio Grande do Sul. 5. ed. Porto Alegre: UFRGS, 1998. $173 \mathrm{p}$.

SIMÕES, C. M. O.; SCHENKEL, E. P. A Pesquisa e a produção brasileira de medicamentos a partir de plantas medicinais: a necessária interação da indústria com a academia. Rev. Bras. Farmacogn. v. 12, n.1, p. 35- 40, 2002.

SOARES, M. S. J. et al. Development and chemical characterization of flour obteined from mesocarpo of "pequizeiro" fruit. Ciênc. Tecnol. Aliment. v. 30, n. 4, p. 949-954, 2010.

STILING, P. T. Ecology: theories and applications. 2. ed. New Jersey: Prentice Hall, 1996. 539 p.

TOMAZZONI, M. I.; NEGRELLE, R. R. B.; CENTA, M. L. Fitoterapia popular: a busca instrumental enquanto prática terapêutica. Texto e Contexto Enfermagem, v. 15, n.1, p. 115-121, 2006.

TYLER, V. E. Natural products and medicine: an overview. In: BALICK, M. J.; ELISABETSKY, E.; LAIRD, S. A. Medicinal resources of the tropical forest, biodiversity and its importance to human health. New York: Columbia University Press, 1996. p. 3-10.

VALIM, Y. M. L. et al. C. Produção de radicais de oxigênio por neutrófilos ativados por diferentes estímulos: função de flavanóides. Departamento de Física e Química: Faculdade de Ciências Farmacêuticas de Ribeirão Preto-Universidade de São Paulo, 2007.

VEIGA, V. F. J. et al. Plantas medicinais: a necessidade de estudos multidisciplinares. Quim. Nova. v. 25, n. 3, p. 429438,2002

VEIGA, V. F. J.; PINTO, A. C.; MACIEL, M. A. M. Plantas medicinais: cura segura? Quim. Nova. v. 28, n. 3, p. 519$28,2005$.

VERA, R. Caracterização física de frutos do pequizeiro (Caryocar brasiliense Camb.) no estado de Goiás. PAT. v. 35, n. 2, p. 71-79, 2005.
VIEIRA, R. F.; COSTA, T. A. Frutas nativas do Cerrado: qualidade nutricional e sabor peculiar. Embrapa Recursos genéticos e biotecnologia. Ambiente Brasil. 2007.

VOGEL, A. I. Química orgânica. 3. ed. Rio de Janeiro: Ao Livro Técnico, 1988. p. 172.

WAGNER, H.; WISENAUER, M. Fitoterapia:

fitofármacos, farmacologia e aplicações clínicas. 2. ed. São Paulo: Pharmabooks, 2006.

WHO. Regulatory situation of herbal medicines. A Worldwide Review, Geneva: WHO, 1998. 45 p.

YUNES, R. A. Plantas medicinais sob a ótica da moderna química medicinal. Chapecó: Argos, 2001.

Recebido: 30/03/2015

Aceito: $28 / 08 / 2015$ 